\title{
Internal Failure of Deep Mixing Columns Reinforced by a Shallow Stabilized Soil Beneath an Embankment
}

\author{
Binh Nguyen $^{1} \cdot$ Tomohide Takeyama $^{2} \cdot$ Masaki Kitazume $^{1}$
}

Received: 25 July 2016/Accepted: 20 September 2016/Published online: 3 October 2016

(C) Springer International Publishing Switzerland 2016

\begin{abstract}
The isolated deep mixing columns, particularly the columns near the slope of the embankment, were reported to experience a minor horizontal resistance while supporting an embankment. In order to reinforce these columns and increase the stability of the improved area, which includes the group of columns, a shallow layer produced by shallow mixing method was proposed as a countermeasure. While many studies reported that the isolated columns may fail either by the external failure or the internal failure, the failure of this combined structure including the deep mixing columns and the shallow layer has not well studied yet. In the previous study, overturning and sliding failures were observed as the leading patterns in terms of the external stability, when the combined structure to supports embankment slope. In addition to the study of the external stability, the internal failure pattern of the columns reinforced by the shallow layer was concentrated in this study. It is worth to note that the lowstrength columns are used here. Four centrifuge model tests were performed by varying the column strengths in models with and without the shallow layer of reinforcement. The results showed a significant influence of the shallow layer on the failure pattern of the deep mixing columns. The study further discusses the effect of the shallow layer and the column strength on the stability of the supported embankment.
\end{abstract}

Keywords Deep mixing method - Shallow mixing · Centrifuge modeling $\cdot$ Failure pattern $\cdot$ Embankment

Binh Nguyen

nttbinh86@gmail.com

1 Department of Civil Engineering, Tokyo Institute of Technology, Tokyo, Japan

2 Department of Civil Engineering, Kobe University, Kobe, Japan

\section{Introduction}

Deep mixing method, as an in situ ground improvement technique, has been reported with various applications in both marine and inland construction [1]. The possibility and the effect of using the deep mixing method, to prevent the slope failure as well as to reduce the settlement of the embankment, dam and levee, were confirmed by many studies [2-5]. This method has been used globally to cutoff seepage and to construct waterfront [5-7]. It was also used to support bridge abutment [8,9] or to make the foundation of buildings $[10,11]$. While working as retaining walls, the method was further used to support a deep excavation [12-14]. During an earthquake, the method was used as a potential countermeasure against liquefaction [15-17]. Additionally, the method was also applicable to environmental issues such as the treatment of the dredge soil [18] and landfill [19].

When using the deep mixing columns to support an embankment slope, Kitazume reported that the columns tend to fail under high embankment pressure, regardless of the strength of the columns $[20,21]$ due to the low horizontal resistance of the column group. The columns may fail either external stability or internal stability, depending on the improvement condition and the ground condition. In particular, the external failure was defined as the failure caused a large displacement of the columns without any failure inside the columns. The internal failure is related to the breakdown of the columns under various patterns such as shearing, bending, compression, tension. As a solution to increase the horizontal resistance of the group of isolated columns, the shallow mixing technique has been used to construct a stabilized layer to fix and reinforce the columns. Several research works were done to investigate the efficacy of the shallow layer on reducing settlement of the 
supported embankment on the soft ground [22, 23] as well as on improving the stability of an embankment slope [24]. To apply the technique, the failure mechanism of the combined structure, including the columns and the shallow layer, should be studied. In a previous study [25], the authors conducted centrifuge model tests to investigate the external failure modes of the combined structure. While the tilting failure was observed as the main failure mode of the isolated columns, the overturning failure took place significantly when applying the shallow layer of reinforcement. As a further study, the model tests were also carried out in this research to investigate the internal failure mode of the combined structure where the columns and the shallow layer with a low strength were considered. For this purpose, the mixtures of Kaolin clay and cement were used to make the columns and the stabilized layer. The sandraining technique [26] was used to construct the embankment during centrifuge flight at the acceleration of $50 \times g$. Four model tests were performed with two different strengths of the columns, while the embankment slope was supported by either the isolated columns or the columns and the stabilized layer. One of the significant conclusions is that the shallow layer has a strong effect on changing the failure pattern of the columns subjected to embankment load. A simple calculation was also conducted to evaluate the internal failure modes, obtained from the model results. The effects of the shallow stabilized layer, as well as the column strength on the stability of the supported embankment, are also addressed in this study.

\section{Apparatus and Equipment}

Together with a series of centrifuge model tests in our previous study [25], the same geotechnical centrifuge at Tokyo Institute of Technology [27] and a rectangular model container [25] were also used in this research. The front window of the container was made of transparent acrylic which allows visual observation during centrifuge flight. The difference from the previous study [25] is the strength of the column and the stabilized layer while a low strength was focused on studying the internal failure pattern of the combined structure. In addition, the embankment constructing process was simulated by the sand-raining technique [28, 29] with an in-flight sand hopper [25].

\section{Model Ground}

\section{Test Condition}

In the ground model, a soft clay layer depositing on a stiff sand layer was simulated by Kaolin clay with the thickness of $200 \mathrm{~mm}$, as can be seen in Fig. 1a. A bisymmetric embankment was built on the clay layer at the right-hand side of the model ground. A group of 12 deep mixing columns was installed at the slope of the embankment to improve the slope stability. The detailed arrangement of the columns is shown in Fig. 1b, in the model scale dimension. In the model tests with the shallow stabilized layer, all columns were fixed and reinforced by this layer with the thickness of $40 \mathrm{~mm}$. The condition of model ground was kept the same for four test cases, as shown in Table 1. In the table, four model tests were performed with two different strengths of the column. The effect of the shallow layer of reinforcement was studied by comparing between the tests with isolated columns and that with the combined structure. The model tests were performed at the centrifugal acceleration of $50 \times g$, while the dimensions of the prototype scale are also displayed in Fig. 1a, in the parentheses.

a

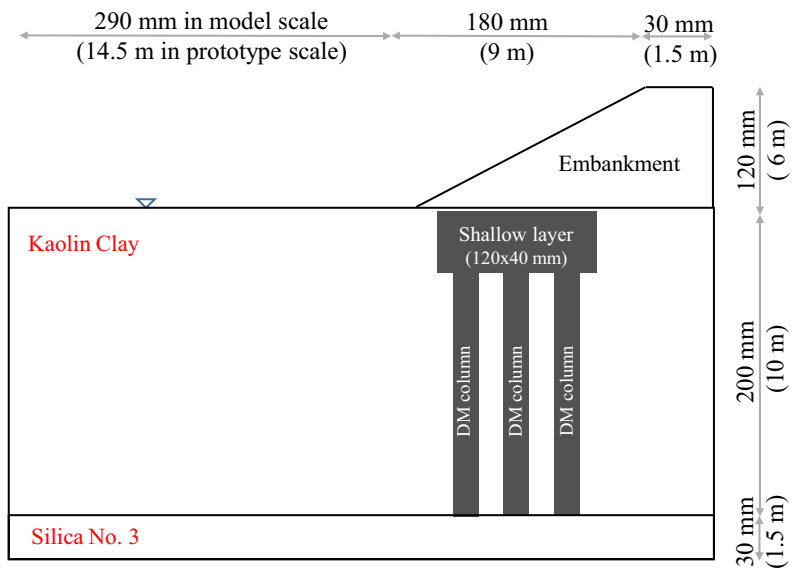

b

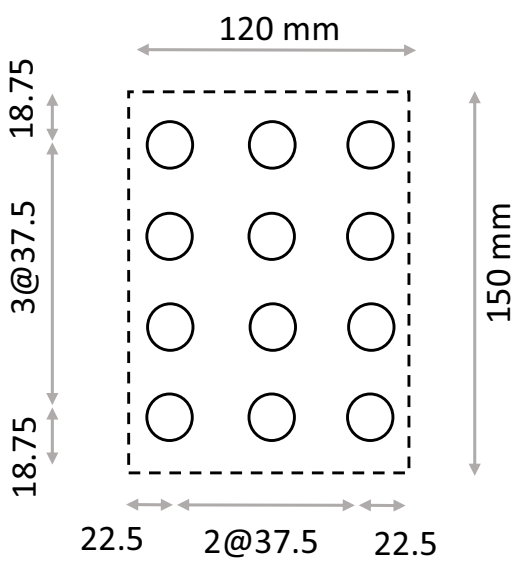

Fig. 1 Model ground condition of centrifuge tests (model scale). a Model ground. b Plan view of columns' pattern 
Table 1 Test cases

\begin{tabular}{lllll}
\hline Test cases & Case 1 & Case 2 & Case 3 & Case 4 \\
Test condition & $q_{\mathrm{u}}=500(\mathrm{kPa})$ & $\begin{array}{l}q_{\mathrm{u}}=500(\mathrm{kPa}) \\
\text { Without SL }\end{array}$ & $\begin{array}{l}q_{\mathrm{u}}=250(\mathrm{kPa}) \\
\text { With SL }\end{array}$ & $\begin{array}{l}q_{\mathrm{u}}=250(\mathrm{kPa}) \\
\text { Without SL }\end{array}$ \\
\hline Columns, $q_{\mathrm{u}}(\mathrm{kPa})$ & 494.9 & 494.9 & 258.3 & 258.3 \\
Shallow layer, $q_{\mathrm{u}}(\mathrm{kPa})$ & 269.7 & - & 164.1 & - \\
Clay layer, $s_{\mathrm{u}}(\mathrm{kPa})$ & 34.5 & 31.2 & 30.1 & 30.7 \\
Final embankment height $(\mathrm{m})$ & 3.94 & 5 & 4.85 & 4.24 \\
\hline
\end{tabular}

\section{Materials}

\section{Model Ground}

In the model ground, the stiff sand layer at the bottom was made by Silica No. 3 [30] with the friction angle of 41 degrees [25]. On the sand layer, Kaolin clay [27] was used to model the soft ground layer where its shear strength is shown in Table 1. To achieve the failure of model ground, the high pressure of the embankment was required. Zircon sand with the high specific gravity of 4.66 [30] was used as the embankment material. The friction angle of 34 degrees and the unit weight of $33 \mathrm{kN} / \mathrm{m}^{3}$ were confirmed for the Zircon sand in the tests.

\section{Soil Cement Mixture}

In the previous study [25], acrylic was used to simulate the columns and the shallow layer with a high strength, to study the external failure modes of the improved area. In this study, soil-cement mixtures including Kaolin powder, water, and ordinary Portland cement was used to make the model columns and the shallow layer for the model tests [21]. The detailed chemical components of the cement are listed in Table 2, according to the Japanese Industrial Standard. Many trials of soil-cement mixture were performed to achieve the targeted strengths of the columns. The unconfined compressive strengths $\left(q_{\mathrm{u}}\right)$ of the column and the shallow layer are presented in Table 1.

In particular, the columns were made by pouring the soil-cement mixture into an acrylic tube with the inner diameter of $20 \mathrm{~mm}$. After curing in a moisture condition for about 3 months, the columns were then extracted out of the acrylic tube and trimmed for the final length of $200 \mathrm{~mm}$ before using in the centrifuge tests. For easily pouring the soil-cement mixture into the tube, the mixture should be slurry or liquid. Therefore, the required water content of the mixture was quite high. However, to achieve the targeted strength of the columns, a high content of cement was also required. Many trials were made and tested to find the suitable mixing condition. As a result, the mixture with the water content of $160 \%$ and the cement content of $30 \%$ was used to make the column with the unconfined compression strength of $500 \mathrm{kPa}$. Although the cement content of $30 \%$ may not be popular, the column strength with $q_{\mathrm{u}}=500 \mathrm{kPa}$ is popular in a real application of the deep mixing method. In addition, another set of column strength was made by the mixture with the water content of 120 and $10 \%$ of the cement content for the targeted strength of $250 \mathrm{kPa}$.

The unconfined compressive test was conducted on the sample with a typical size, $50 \mathrm{~mm}$ in diameter and $100 \mathrm{~mm}$ in height. The result for unconfined compressive strength with time is shown in Fig. 2a, while the relationship between the unconfined compressive strength and Young modulus, $E$, is presented in Fig. 2b for two sets of soilcement mixture. Although a large scatter in the $q_{\mathrm{u}}$ value of the columns was observed, the average value was confirmed about $500 \mathrm{kPa}$ after 100-day curing. With shorter curing time, about 14 days, the shallow layer has the $q_{\mathrm{u}}$ of $270 \mathrm{kPa}$ for the same soil-cement mixture, which was about $60 \%$ that of the columns. The Young modulus was observed about 150 times the $q_{\mathrm{u}}$ value, as shown in Fig. $2 \mathrm{~b}$ for the columns with a higher strength. Similarly, for the columns with a lower strength, the average value of $q_{\mathrm{u}}$ was observed about $250 \mathrm{kPa}$ at 150-day curing while after 14-day curing the strength was about $165 \mathrm{kPa}$ at the centrifuge test.

\section{Preparation and Test Procedure}

The preparation was started by pouring Silica No. 3 into the model container to make the stiff bottom layer. The soft clay layer was made by consolidating Kaolin clay slurry with the initial water content of $100 \%$ under a consolidating pressure of $200 \mathrm{kPa}$. The water content and shear strength of the consolidated clay were measured and shown in Fig. 3a, b respectively. In the figure, the water content of
Table 2 Chemical components of Japanese ordinary Portland cement

\begin{tabular}{llllll}
\hline $\mathrm{CaO}(\%)$ & $\mathrm{SiO}_{2}(\%)$ & $\mathrm{Al}_{2} \mathrm{O}_{4}(\%)$ & $\mathrm{Fe}_{2} \mathrm{O}_{4}(\%)$ & $\mathrm{SO}_{4}(\%)$ & Others \\
\hline $64-65$ & $20-24$ & $4.8-5.8$ & $2.5-4.6$ & $1.5-2.4$ & $\mathrm{MgO}, \mathrm{Na}_{2} \mathrm{O}, \mathrm{K}_{2} \mathrm{O}, \mathrm{MnO}, \mathrm{P}_{2} \mathrm{O}_{5}$ \\
\hline
\end{tabular}



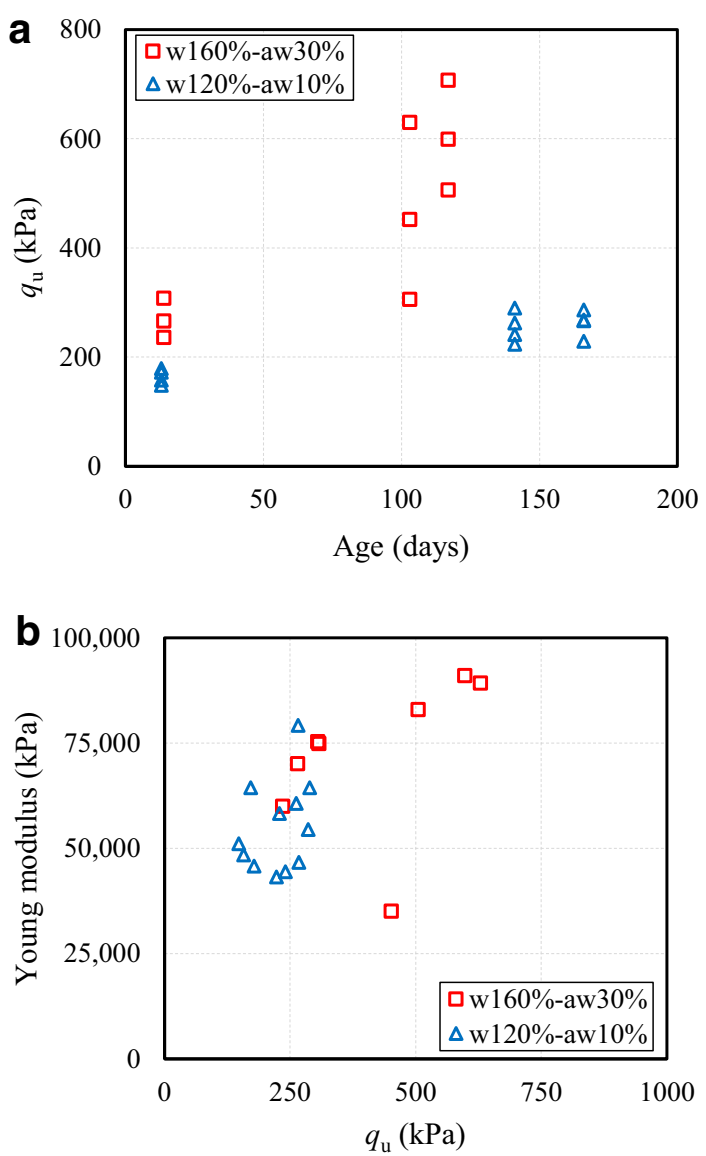

Fig. 2 Strength and stiffness of the mixing materials. a Unconfined compressive strength. b Young modulus

about $60 \%$ and about $30 \mathrm{kPa}$ of shear strength were confirmed along the depth of the clay layer through four cases. The water content which was estimated from laboratory tests was also plotted in Fig. $3 \mathrm{a}$ as the broken line to confirm the results of preparation of the clay layer.

The front window of the model container was then disassembled for attaching the optical markers [25], which were later used to measure the displacement of the subsoil with the optical measurement techniques.

After reassembling the container window, the process was continued by installing the model columns into the clay layer at projected positions. A thin-walled tube was then inserted into the clay layer, located by a guiding plate. The soil inside the tube was removed by a small auger. The columns were carefully inserted into the holes after withdrawing the tube from the clay layer. In the test with the shallow layer, the space for the layer was excavated before installing the columns. After the column setup, the shallow layer made by the soil-cement mixture was then cast and cured inside the model container for 14 days before performing the centrifuge test. The preparation of ground model before placing the model container into the
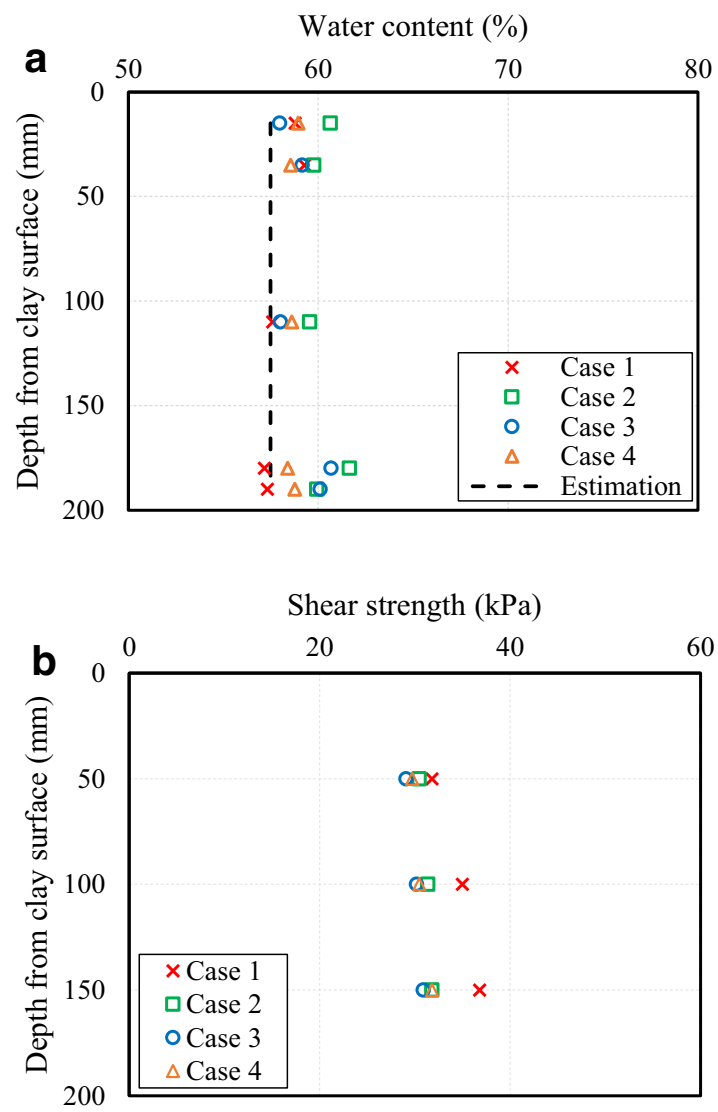

Fig. 3 Water content and shear strength of the Kaolin clay layer. a Water content. b Shear strength

centrifuge platform is shown in Fig. 4 a for Case 1 as a typical example. In Fig. 4b, the instruments used in the model tests are clearly shown with schematic figures for the front and side views of the ground model. Specifically, as can be seen in Fig. 4b-i, a sand hopper was assembled at the top-right side of the container while the Zircon sand was filled in the hopper. Under the center of constructed embankment, two earth pressure gauges were early placed to measure the embankment pressure during construction. The sand-raining technique is significantly affected by the Coriolis force due to the spinning of the centrifuge. When the model container was spun in the direction from the front to the rear side of the container, the sand in the hopper flows toward the front side of the container which causes a higher embankment at the side. Several wings were attached under the sand hopper to adjust the falling direction of sand as described in Fig. 4b-ii. The angles of the wings and the difference of the height of the Zircon sand in the hopper along the spinning direction were adjusted through calibration test to obtain a flat embankment.

The centrifuge test was carried out with the centrifugal acceleration of $50 \times g$ while the expected acceleration was set on the surface of the clay layer. The model ground may 


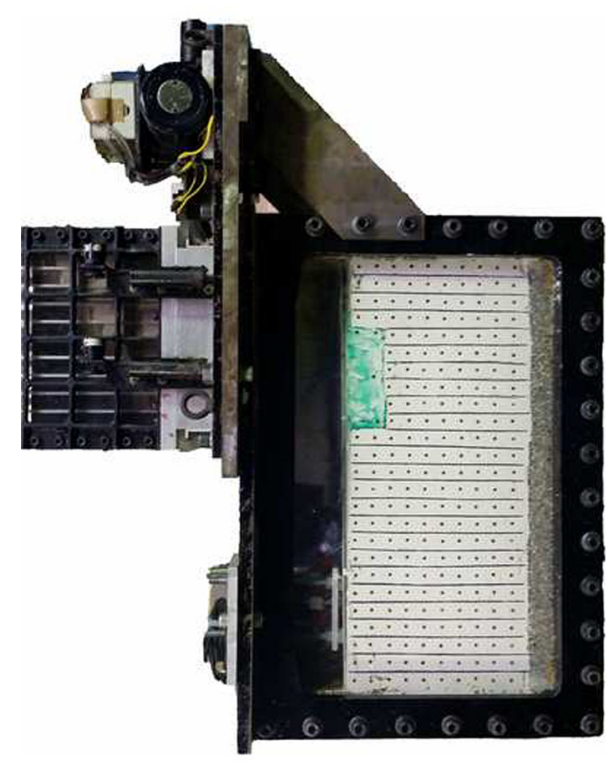

a

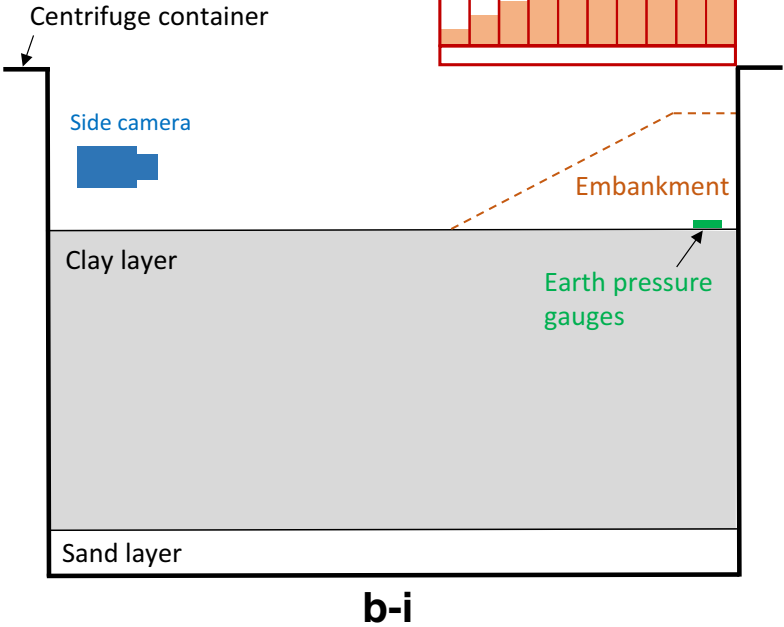

Spinning direction
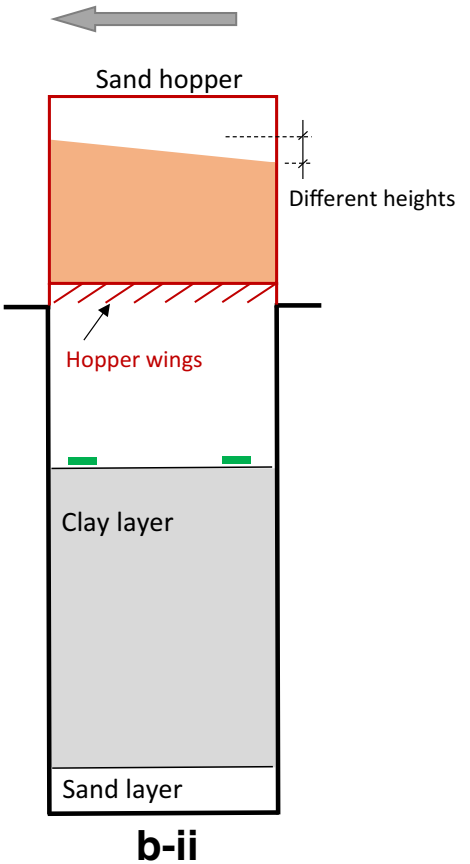

Fig. 4 Preparation of ground model. a Ground model before centrifuge test (Case 1). b Instrument set-up

experience different accelerating levels due to the difference of spinning radius at various positions of the ground model. At the bottom of the clay layer, the ground model experienced an acceleration of $55 \times g$, which may not significantly influence the results of the model tests.

\section{Optical Measurement Techniques}

A digital camera was set up to capture the front view of the model ground through the Perspex window when constructing the embankment. The captured photos were later used to measure the movement of the subsoil by using the optical measurement technique. For general deformation of the model ground, the Particle Image Velocimetry (PIV) technique [31, 32] was used to chase the movement of certain patches indicated by optical makers at the clay layer. The optical markers were made by $10 \mathrm{~mm}$-long nails and were expected to move with the same movement of the subsoil. The PIV technique can be automatically and easily performed by using the GeoPiV software [33]. The technique can save time and effort to measure a large number of images and optical markers. However, the accuracy is 
strongly influenced by the image quality. Due to the poor condition of the light in the centrifuge spinning room, the technique was only used to obtain the movement of model ground in overall. In addition, to measure the detailed displacement of the model ground, the movement of the optical markers were carefully tracked by using the Particle Tracking Velocimetry (PTV) technique [34, 35]. The movement of the markers was manually measured with the assistance of a computer. The PTV measurement consumed a lot of time and effort while measuring a large number of optical markers through many images. Therefore, the PTV technique was only used to obtain the movement of certain markers including the embankment toe, embankment center, and the markers which respect the column positions. By using the large-sized markers (4 $\mathrm{mm}$ in diameter) together with high-quality photos, taken by a high-speed camera, the accuracy of PTV method obtained by manual measurement was confirmed about \pm 0.1 pixels $( \pm 0.65 \mathrm{~mm}$ in model scale) in the movement of the markers. The accuracy of using this PTV technique was also confirmed by comparing the final displacement of the columns, obtained from PTV, to that measured from excavated columns after centrifuge tests. The detailed comparison was shown later in the discussion section. Although there was a slight difference on the results of two methods, the PTV was sufficient for measuring the subsoil displacement and the column deformation.

\section{Results and Discussion}

\section{Embankment Pressures}

The embankment pressures during construction measured by earth pressure gauges in four cases are shown in Fig. 5 . Although all tests were designed to have the same loading condition for studying the undrained behavior of the model ground, the loading condition in Cases 1 accidentally lasted for a longer time, which might cause a drained behavior in

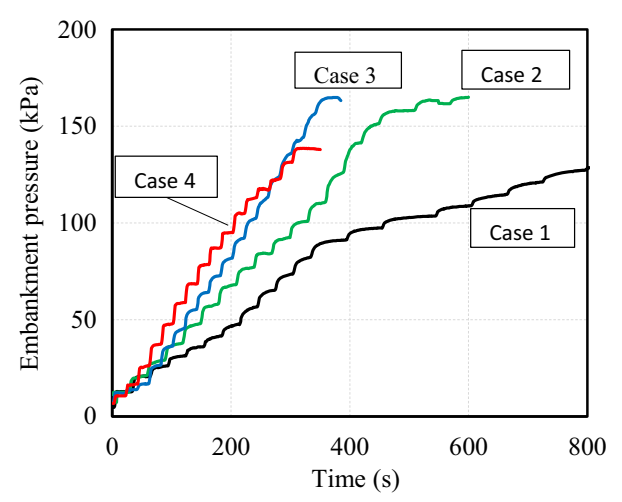

Fig. 5 Average embankment pressures during construction the model ground. In order to confirm the undrained loading condition, the volume change of model ground was measured by comparing the volume before and after constructing the embankment. Fortunately, the volume was confirmed with no change after the centrifuge tests for all test cases. As a result, the model ground experienced the undrained loading condition in all cases as expected. In addition, for studying the failure mechanism of the columns, a heavy failure of model ground and the columns should be avoided. Therefore, four centrifuge tests were stopped at four different embankment pressures, dependent on the column strength and the use of the shallow layer, as shown in Fig. 5. The model tests were stopped by reducing g-level to 1 -g condition, right after the final loading of embankment construction, to avoid the time effect on the deformation of the model ground.

\section{Shear Strain Distribution of Model Ground}

The distributions of the maximum shear strain of model ground measured from the movement of optical markers (PIV) are shown in Fig. 6 for all tests at different final pressures of the embankment. Specifically, for the tests with higher-strength columns $\left(q_{\mathrm{u}}=500 \mathrm{kPa}\right)$ as shown in Fig. 6a, the strain fields are presented for Case 1 and Case 2 on the left and right photos respectively. In the left-hand, even at the embankment pressure of $130 \mathrm{kPa}$, with a minor strain of the model ground, an obvious failure did not happen. However, a clear failure of the model ground in Case 2 without the shallow layer was confirmed with a large strain at the embankment pressure of $165 \mathrm{kPa}$. The maximum strain of $20 \%$ was observed right under the embankment as shown in the right-hand graph. By turning to the strain distribution for lower strength columns $\left(q_{\mathrm{u}}=250 \mathrm{kPa}\right)$ in Fig. 6b, the shear strain was presented for Case 3 (the left graph) and Case 4 (the right graph). Results show an obvious failure of model ground at the final embankment pressures for both tests with a large strain. The maximum strain was found around $20 \%$ for both test cases at the final loadings. Similar to Case 1 and Case 2, the strains in Case 3 and Case 4 were also significant under the embankment and reduced to the toe side of the embankment.

\section{Displacements of the Embankment}

The prototype scale is used for presenting the centrifuge test results and discussions in detailed deformation from this section. The prototype dimension of the ground model is also presented in Fig. 1a (in parentheses). By using the PTV measurement, the horizontal displacement at the embankment toe and the settlement under the embankment in four tests are plotted against the embankment pressure in 


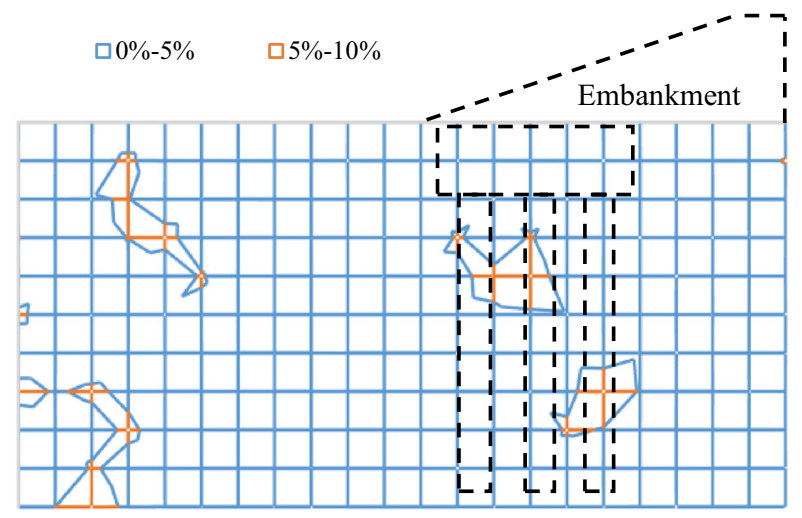

a-i

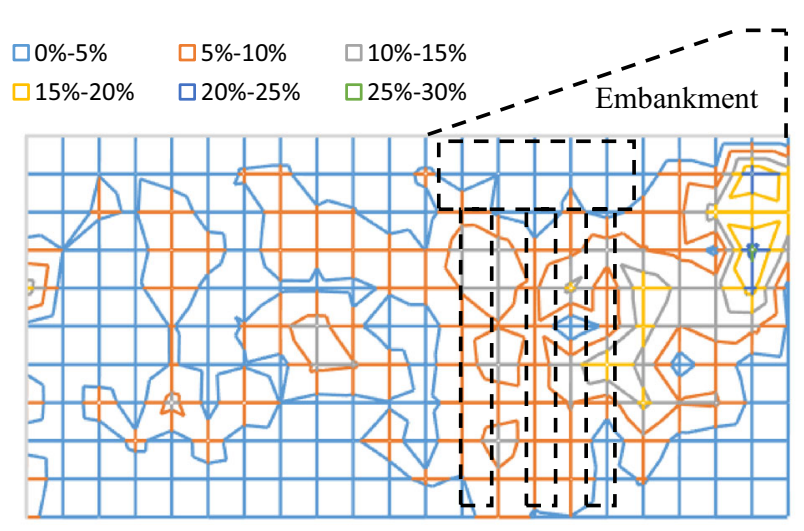

b-i

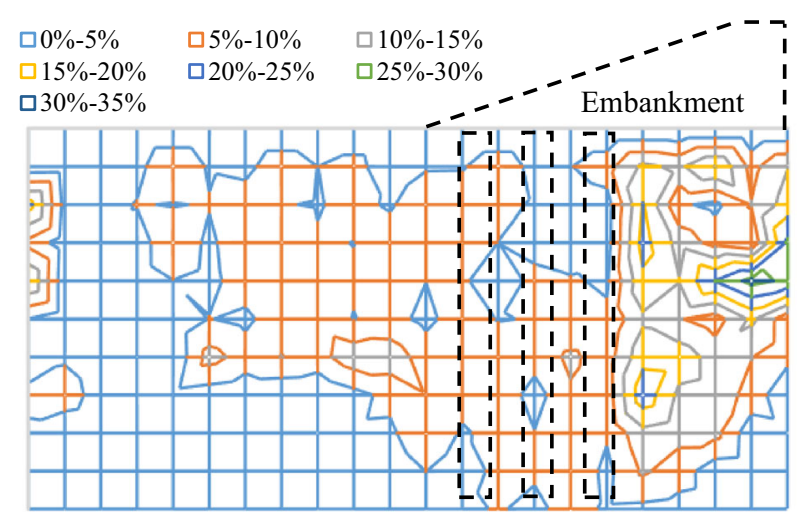

a-ii

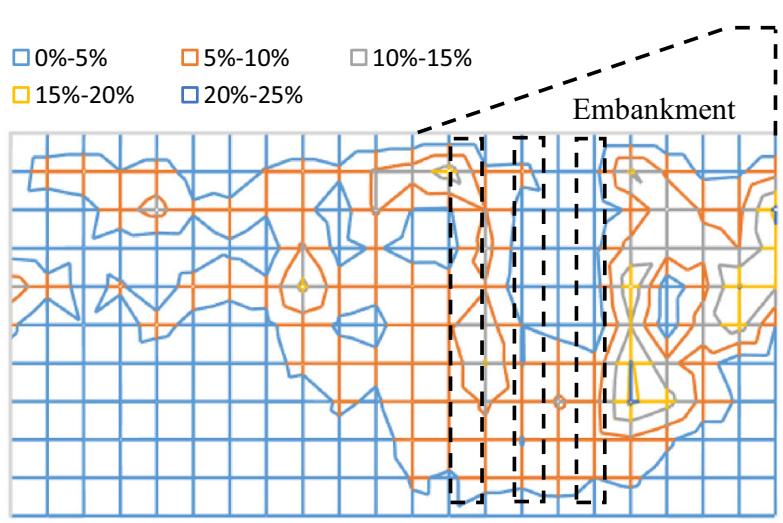

b-ii

Fig. 6 Shear strain distribution (by PIV measurement). a Higher strength columns $\left(q_{\mathrm{u}}=500 \mathrm{kPa}\right)$. $i$ Case 1 at Pe $=130 \mathrm{kPa}$. $i i \mathrm{Case} 2$ at Pe $=$ $165 \mathrm{kPa}$. b Lower strength columns $\left(q_{\mathrm{u}}=250 \mathrm{kPa}\right)$. $i$ Case 3 at $\mathrm{Pe}=160 \mathrm{kPa}$. $i$ Case 4 at $\mathrm{Pe}=140 \mathrm{kPa}$. (Color figure online)

Fig. 7. While the horizontal displacement of embankment increased with embankment pressure as shown in Fig. 7a, the magnitude of displacement was various for each test. Smaller displacement took place at the embankment toe when the shallow layer was applied to reinforce the isolated columns irrespective of the column strength. In addition, with a higher strength of columns, the horizontal displacement also reduced considerably regardless of the use of the shallow layer. By turning to the settlement in Fig. 7b, the greatest settlement occurred in Case 4 for the embankment supported by the lower-strength columns without the shallow layer of reinforcement, especially with the large pressure of the embankment.

The embankment pressure at a clear bending point in the load-displacement curve (in Fig. 7a) so-called yield pressure is used to evaluate the stability of the supported embankment. The yield pressures were obtained by replotted the graph in Fig. 7a in the semi-logarithmic scale, for the ease of determination of bending points. As a result, the yield pressures were obtained for Case 2, 3 and 4 at 90 , 100 , and $70 \mathrm{kPa}$ respectively, as can be seen in Fig. 8 .
These pressures can be considered as the loading when the embankment is about to fail. The results of yield pressure for all tests are plotted together in Fig. 9. In Case 1, the yield pressure cannot be obtained due to the linear relationship between the displacement and the embankment pressure until the final loading of $130 \mathrm{kPa}$. The yield pressure was expected greater than $130 \mathrm{kPa}$. For discussion, the embankment pressure of $130 \mathrm{kPa}$ is taken into account. By looking at the diamond marks in Fig. 9, the yield pressure of $90 \mathrm{kPa}$ in Case 2, is much smaller than the assumed yield pressure of $130 \mathrm{kPa}$ in Case 1 when considering the effect of the shallow layer for the columns with $q_{\mathrm{u}}=500 \mathrm{kPa}$. Furthermore, for the columns with $q_{\mathrm{u}}=250 \mathrm{kPa}$, the yield pressure increased from 70 to $100 \mathrm{kPa}$ when applying the shallow layer of reinforcement. It can be said that by using the shallow layer to reinforce the isolated columns, the embankment pressure at yield increases significantly regardless of the column strength. Additionally, the increment of the yield pressure is confirmed with the increment of the column strength in both cases with and without the shallow layer. 

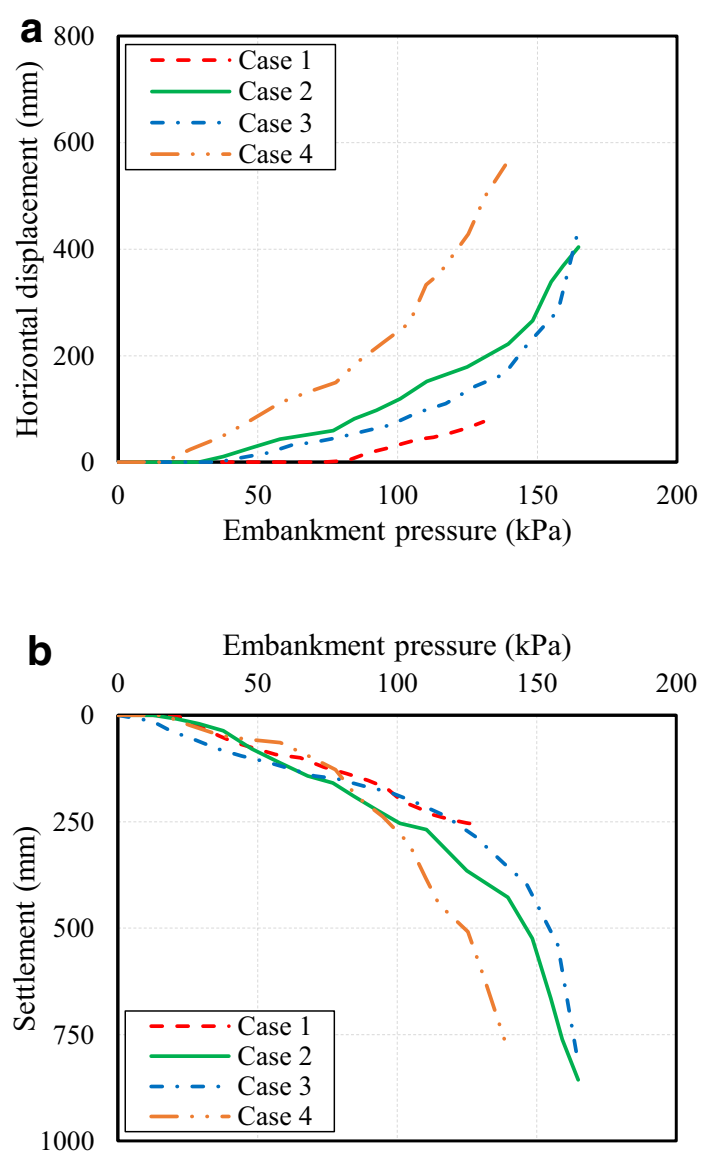

Fig. 7 Embankment displacements. a Horizontal displacement at embankment toe. b Settlement under embankment

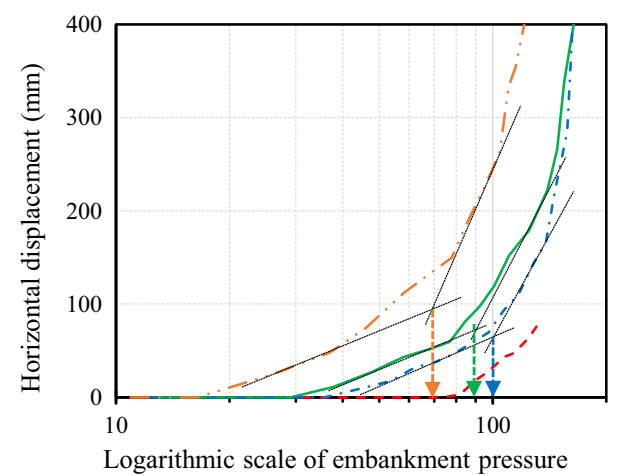

Fig. 8 Obtaining yield pressures from the horizontal displacements of embankment

To evaluate the effect of the shallow layer and the column strength on reducing the displacement of the supported embankment, the horizontal displacements at embankment toe in four centrifuge tests are plotted together at the same embankment pressure of $130 \mathrm{kPa}$ in Fig. 10. First, the horizontal displacement was reduced considerably when the isolated columns were reinforced by the shallow layer. Specifically, the displacement decreased

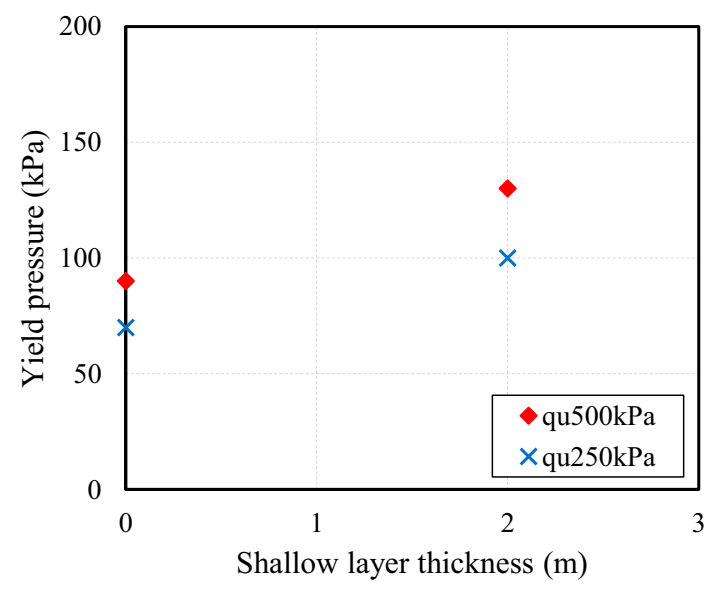

Fig. 9 Embankment pressure at yield

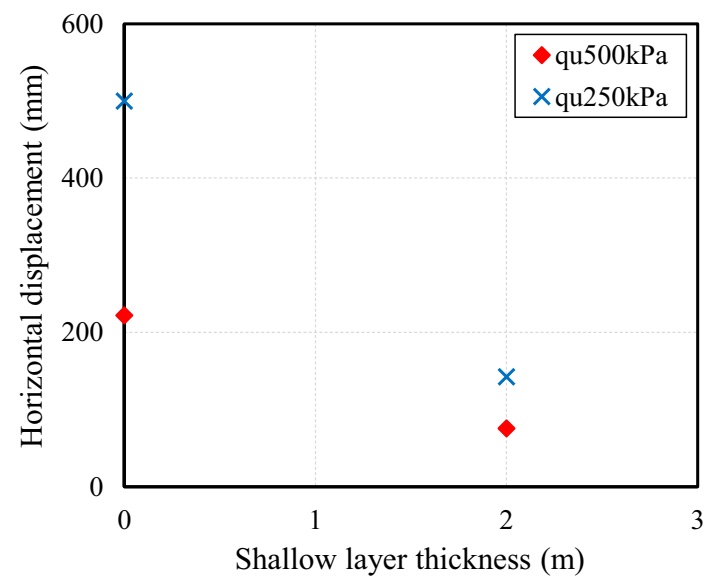

Fig. 10 Horizontal displacement at embankment toe $\left(P_{\mathrm{e}}=130 \mathrm{kPa}\right)$

from 220 to $70 \mathrm{~mm}$ for the higher strength columns while the displacement went down to $140 \mathrm{~mm}$ from $500 \mathrm{~mm}$ for the lower strength one. The results confirm that about $70 \%$ of the displacement was reduced when using the shallow layer in the circumstance of this study. Second, the column strength also had a strong influence on the displacement of the embankment. As can be seen in Fig. 10, about $50 \%$ decrement in the horizontal displacement was confirmed when increasing the $q_{\mathrm{u}}$ value of the columns from 250 to $500 \mathrm{kPa}$ even with or without the shallow layer.

The significant increment of the yield pressure and the large decrement of the embankment displacement were observed when the isolated columns were reinforced by the shallow layer. It can be concluded that the shallow layer has a strong effect on increasing the stability of the embankment supported by deep mixing columns. The effect of the surface-improved layer on increasing the failure pressure of the column-supported embankment was also reported by Kitazume [24]. Additionally, the column 
strength also remarkably affects the stability of the embankment.

\section{Failure of Deep Mixing Columns}

The deformation of the columns was measured by two methods including the PTV technique during constructing the embankment and the measurement of the excavated columns after stopping the centrifuge. The comparison in Case 2 as a typical example is shown in Fig. 11. The reliability of the use of the optical markers was confirmed by a good agreement between two methods with the same magnitude of columns' deformation.

The exposed columns by excavating surrounding clay after centrifuge tests are shown in Fig. 12 for all tests. By looking at Fig. 12a for the final deformation of columns with $q_{\mathrm{u}}=500 \mathrm{kPa}$, small cracks were found at the connection between the columns and the shallow layer in Case 1 as shown in the left-hand photo. The largest crack can be observed in the front column, which was located near the toe side of the embankment. On the failure of the isolated columns in Case 2, bending failure obviously took place in all three columns as the main failure pattern. Due to the bending failure, there are many tensile cracks appearing the middle part of the columns. Similarly, the same deformation pattern was also observed for the lower strength columns in Fig. 12b. Large tensile cracks can be obviously seen at the connection between the shallow layer and the columns for Case 3 in Fig. 12b-i. In addition, the failure due to large compressive stress was also found at the bottom of the rear column. As shown in Fig. 12b-ii, the isolated column in Case 4 experienced a bending failure with many tensile cracks appearing at the middle depth of these columns.

In order to compare the deformation of the columns amongst four model tests, the deformation of these columns is plotted together for various embankment pressures

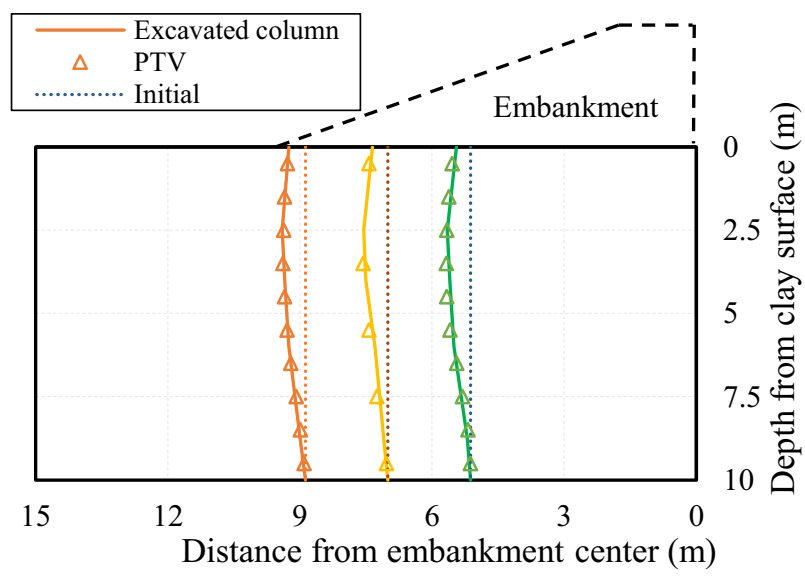

Fig. 11 Comparison between PTV and measured results (Case 2) in Fig. 13. Through the Perspex face, the deformation was measured from the movement of the optical markers, which respect the positions of the columns inside the model ground. The PTV technique, with a manual measurement, was adopted in this observation. Because the deformation pattern and the deformation magnitude of all three columns were almost the same in each test, the deformation of front columns as an example was used for discussion. The deformations of the columns were measured at three different pressures of the embankment as shown in Fig. 13. At a low level of the embankment pressure in Fig. 13a $\left(P_{\mathrm{e}}=50 \mathrm{kPa}\right)$, the deformation of the columns in all tests was almost the same because the model grounds did not fail at the current loading. However, the difference on the deformation of the column among four tests is clearly observed in Fig. 13b with a higher pressure of $100 \mathrm{kPa}$.

The effects of the column strength and the shallow layer on the deformation of columns can be clearly observed at the embankment pressure of $130 \mathrm{kPa}$ (Fig. 13c) due to the considerable difference in the deformation magnitude of the column. In details, the isolated columns displaced greater than that reinforced by the shallow layer. Less displacement was observed in the columns with a higher strength regardless of the use of the shallow layer. Regarding failure pattern as shown in Fig. 13c, although the cracks were observed at the connection between the shallow layer and the columns, the columns still kept its straight shape without any bending along the column depth. By contrast, the isolated columns experienced a large bending when the shape of columns changed to a curve with many cracks as shown in Fig. 12. The failure mechanism and shape pattern of the isolated columns beneath an embankment slope at the failure state were also confirmed by previous studies [21, 36, 37].

\section{Effect of Shallow Layer and Column Strength on the Failure of Deep Mixing Columns}

The discussion, on the internal failure pattern of deep mixing columns, will focus on two main factors, including the shallow layer and the column strength. First, in Fig. 14, the failure of columns was plotted together with the displacement vector of model ground at the final loading of the embankment to fully understand the failure mechanism of the improved ground. The failure of the supported embankment and the improved ground is mainly influenced by the failure of the improved area including the columns and the shallow layer. Results of displacement vectors were obtained by using the PIV technique. For higher strength columns, Fig. 14a-i shows the columns in Case 1 which experienced cracks at the connection between the shallow layer and the columns. However, the failure of model ground did not happen at the embankment pressure of 


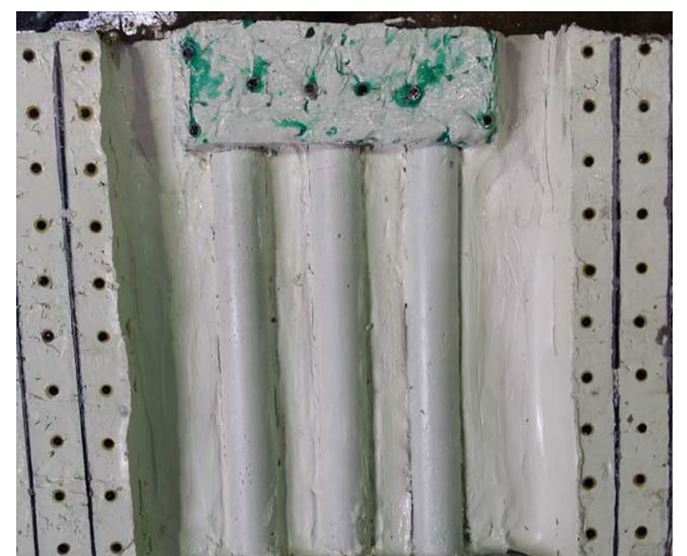

a-i

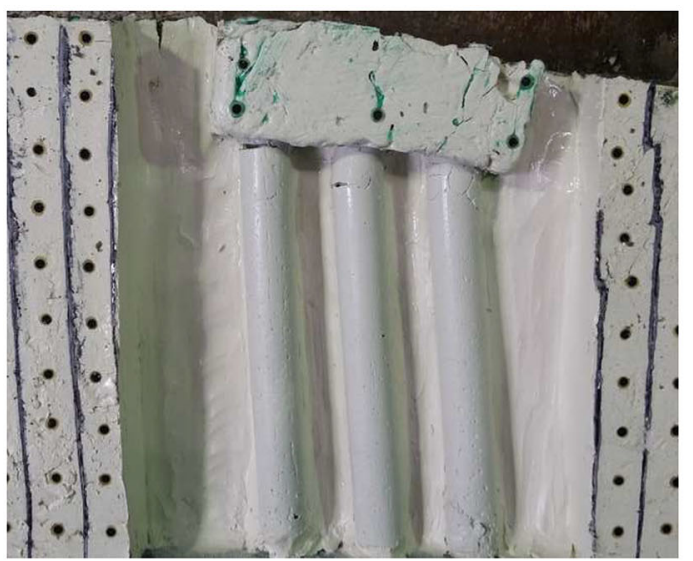

b-i

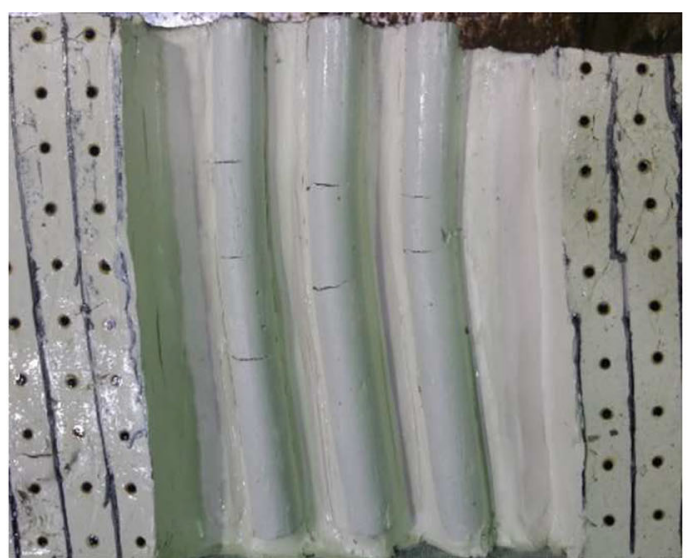

a-ii

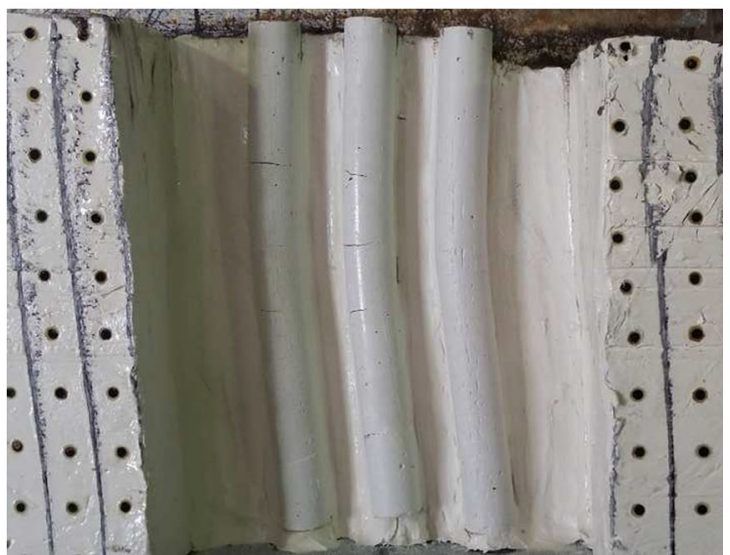

b-ii

Fig. 12 Excavated columns after centrifuge tests. a Higher strength columns $\left(q_{\mathrm{u}}=500 \mathrm{kPa}\right), i$ Case 1 at $P \mathrm{e}=130 \mathrm{kPa}$, $i i \mathrm{Case} 2$ at $P \mathrm{e}=165$ $\mathrm{kPa}$. b Lower strength columns $\left(q_{\mathrm{u}}=250 \mathrm{kPa}\right), i$ Case 3 at $P \mathrm{e}=160 \mathrm{kPa}$, ii Case 4 at $P \mathrm{e}=140 \mathrm{kPa}$

$130 \mathrm{kPa}$ even the tensile cracks took place in all three columns. Except for the cracks at the connecting position, no crack was found along with other depth of the columns. By contrast, in Case 2 with the isolated columns, due to cracks at the middle depth of the columns (Fig. 14a-ii), heavy failure of improved ground was confirmed with a large displacement.

The same pattern was also observed for the tests with the lower-strength columns as shown in Fig. 14b. In particular, even at serious failure stage, tensile cracks only occurred at the connection in Case 3. Except for the compressive failure at the bottom of the rear columns, no tensile crack took place in other parts of the columns. While the shallow layer overturned, the columns tilted away from the embankment center after the failure happened with large tensile cracks at the connection. Nevertheless, the isolated columns in Case 4 experienced many tensile cracks under a bending failure pattern, which was also confirmed in Case 2. As a result, it can be said that when using the shallow layer, the bending failure of the isolated columns is replaced by the tilting failure after the tensile crack took place in the columns right under the shallow layer. Furthermore, while the isolated columns at the rear side experienced a bending failure, the compressive failure also occurred in the rear columns with the shallow layer. The compressive failure may be caused by the redistribution of embankment pressure on the rear columns with the use of the shallow layer.

Second, by turning to the effect of the column strength on the failure pattern of the columns, the test results showed that despite the difference in the column strengths, the columns shared the same failure modes irrespective of the use of the shallow layer. The bending failure with tensile cracks at the middle depth of the columns is considered as the main failure mode of the isolated columns regardless of the strength of the columns (Case 2 and Case 4 in Fig. 14). Similarly, for the columns with the shallow layer of reinforcement, tilting failure was observed as an important failure mode after tensile cracks appeared in the columns at the connection irrespective of the strength of the columns. It can be concluded that regarding internal failure, the column strength has no effect on the failure mode of the columns regardless of the shallow layer of reinforcement. 


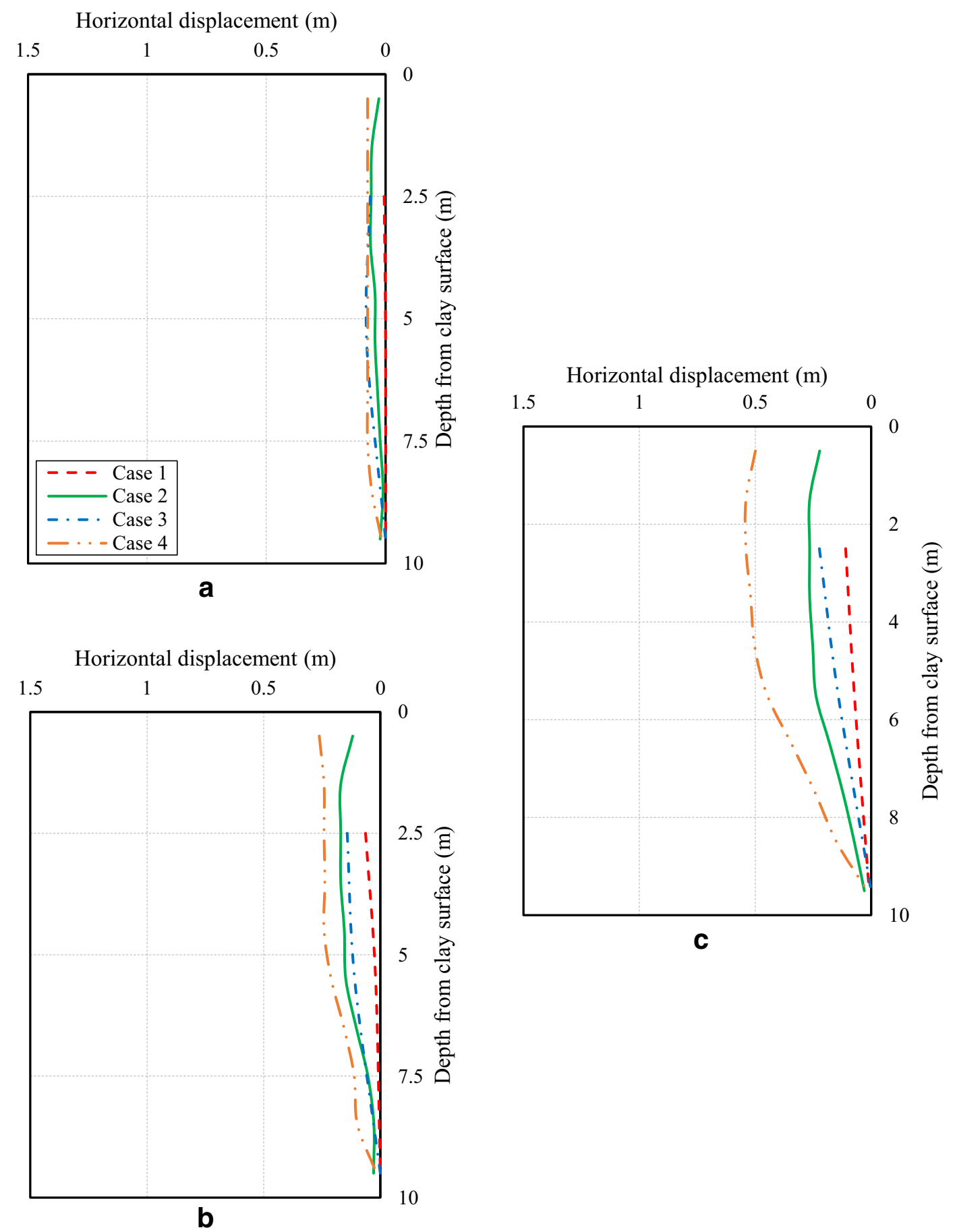

Fig. 13 Comparison of column deformations (front columns). a $P_{\mathrm{e}}=50 \mathrm{kPa}$. b $P_{\mathrm{e}}=100 \mathrm{kPa}$. c $P_{\mathrm{e}}=130 \mathrm{kPa}$

\section{Summary and Conclusions}

While the embankment slope has been conventionally supported by a group of deep mixing columns, the application of a shallow mixing layer to reinforce the isolated columns was concentrated in this study. The centrifuge model tests were performed to simulate the construction of an embankment slope which was supported by the combined structure, including the columns and the shallow layer. This study focused on the internal failure pattern of the columns when the shallow layer was used to reinforce the column group. By comparing to the test with embankment slope supported by isolated columns, the effect of the shallow layer on the failure of columns and on 

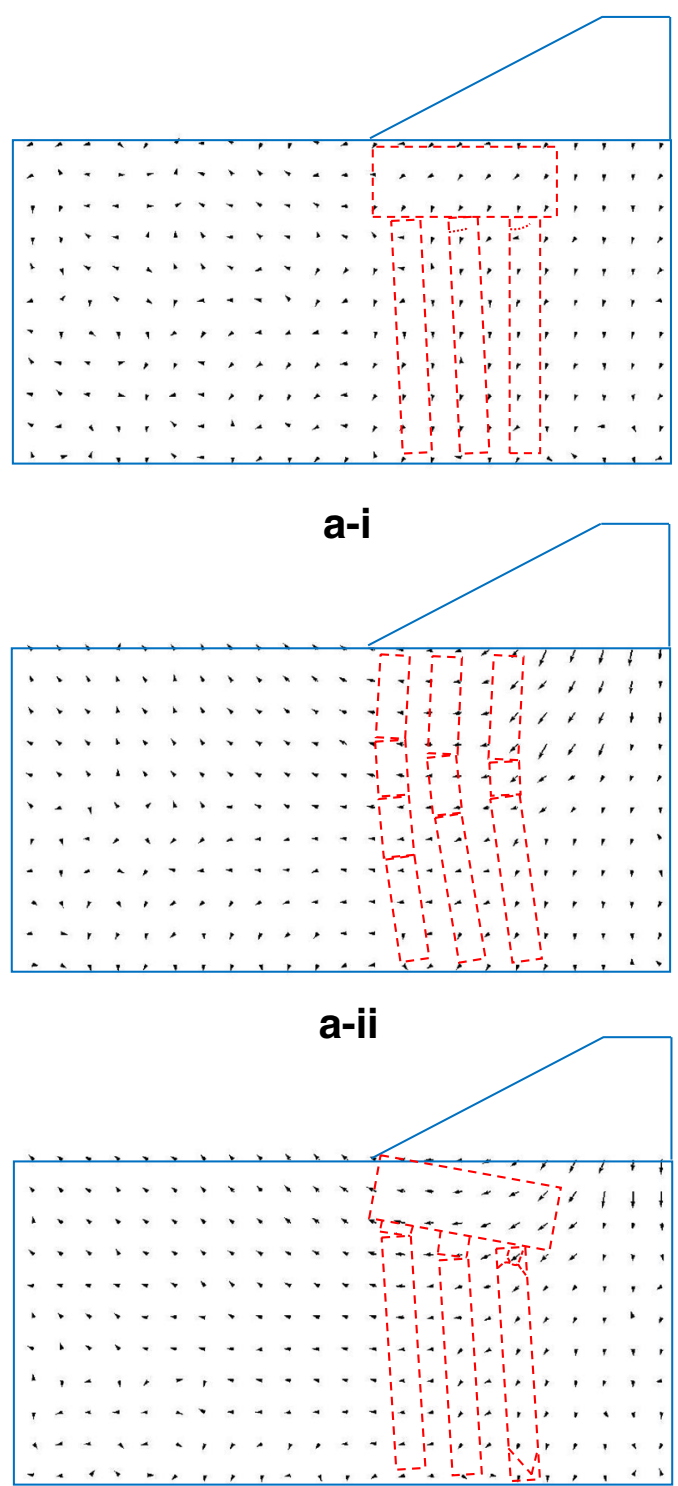

b-i

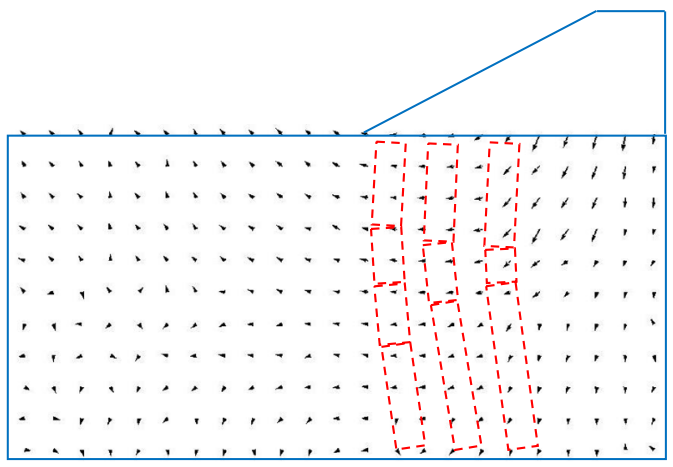

b-ii

Fig. 14 Ground deformation with failure of columns. a Higher strength columns $\left(q_{\mathrm{u}}=500 \mathrm{kPa}\right)$. b Lower strength columns $\left(q_{\mathrm{u}}=250 \mathrm{kPa}\right)$ the stability of the supported embankment can be addressed. The influence of the column strength was also considered on the issues. Thus, some important findings obtained from this study are listed:

- While the shallow layer has a strong influence on the failure pattern of the columns, the column strength has no effect on the issue, in terms of internal stability.

- Bending failure is considered as the main failure pattern of the isolated columns. Tensile cracks under the bending failure were observed at the middle depth of the columns.

- When applying the shallow layer of reinforcement, tensile cracks also take place in the columns at the connection with the shallow layer. The columns then experienced a tilting failure without any tensile crack along other depth of the column. With the use of the shallow layer, the embankment pressure taking place on the columns may be redistributed. Compressive failure may also occur at the rear columns due to the redistribution of the pressure of embankment.

- The shallow layer has a strong effect on increasing the stability of improved ground irrespective of the column strength. An increment in the embankment pressure at yield and a decrement in the horizontal displacement of embankment toe were confirmed by the model tests in this study.

- The effect of the column strength on the stability of the model ground is also considerable regardless of the shallow layer of reinforcement.

\section{References}

1. Kitazume M, Terashi M (2013) The deep mixing method. CRC Press

2. Martel DW, Piling W (2015) Dam wall toe stabilisation using mass soil mixing techniques. In: Deep mixing 2015, pp 181-192

3. Shrestha R, Jose S, Griffin R, Jose S, Cali P, Engineering SL, Kafle S, Jose S, Watanabe M, Jose S, Yang D, Jose S (2015) Deep mixing for levee repair at hurricane protection project. In: Deep Mixing 2015, vol 23, pp 257-266

4. Bertoni M, Schmutzler W (2015) Soil mixing for the LPV-111 levee improvement, New Orleans: a case history. In: Deep mixing 2015, vol 2, pp 247-256

5. Arnold M (2015) Seepage cut-off wall installation using cutter soil mixing for Herbert Hoover dike rehabilitation. In: Deep mixing 2015, vol 727, pp 213-222

6. Tanaka Y, Mitarai Y, Nagatome T, Corporation T, Branch T (2015) Application of large-scale and rapid construction of lightweight stabilized soil with air foam for deep water zone to stabilize existing quay wall. In: Deep mixing 2015, vol c, pp 203-212 
7. Nagatsu T, Uchida K, Kurumada Y (2015) Soil improvement in Marina Coastal Expressway project (C485) with cement deep mixing (CDM) method. In: Deep mixing 2015, pp 467-474

8. Tatsuoka F (2004) Cement-mixed soil for Trans-Tokyo Bay highway and railway bridge abutments. In: Geotechnical engineering for transportation projects, pp 18-76

9. Yamasaki K, Hemstreet D, Gerondale A, Shao L (2015) Wet soil mixing for supporting bridge abutments on spread footings. In: Deep mixing 2015, pp 395-404

10. Rollins KM, Brown DA, Law H (2015) Simplified model for increased lateral resistance of deep foundations using soil mixing. In: Deep mixing 2015, pp 385-394

11. Yamashita K, Tanikawa T, Shigeno Y, Hamada J (2015) Vertical load sharing of piled raft with grid-form deep mixing walls. In: Deep Mixing 2015, pp 437-446

12. Weatherby D, Zywicki D (2012) Deep soil mixed wall and jet grouting for an excavation retention system at museum of fine arts, Boston. In: Grouting and deep mixing 2012, pp 379-388

13. Ruffing D, Sheleheda M, Schindler R (2012) A case study: unreinforced soil mixing for excavation support and bearing capacity improvement. In: Grouting and deep mixing 2012, pp $410-416$

14. Forrest M, Roadifer J, Gorski G (2015) Cement deep soil mixing shear wall stabilization Calaveras dam replacement project, California. In: Deep mixing 2015, pp 299-308

15. Arora S, Shao L, Schultz J (2012) Wet soil mixing for bearing capacity, liquefaction mitigation, and water cutoff for scour protection for a new bridge abutment. In: Grouting and Deep mixing 2012, pp 575-584

16. Imai M, Konishi K, Higashinaka K, Honda T, Kaneda K (2015) Experiment to determine the influence of groundwater level on grid-form deep mixing walls for liquefaction control. In: Deep mixing 2015, pp 349-355

17. Rayamajhi D, Tamura S, Khosravi M, Boulanger RW, Wilson DW, Ashford SA, Olgun CG (2015) Investigating reinforcing effects of soil-cement columns in liquefiable sand using dynamic centrifuge tests. In: Deep mixing 2015, pp 375-384

18. Holm G, Macsik J, Makusa G, Kennedy H, Rogbeck Y (2015) Stabilization of materials - upgrading of soils and sediments to use in geo-constructions. In: Deep mixing 2015, pp 405-414

19. Sasa K, Kurumada Y, Watanabe M (2015) Mixing proportion design and construction management for application of cement deep micing method to construction project on controlled final landfill site in Japan. In: Deep mixing 2015, pp 193-202

20. Kitazume M, Maruyama K (2006) External stability of group column type deep mixing im-proved ground under embankment loading. Soils Found 46(3):323-340

21. Kitazume M, Maruyama K (2007) Internal stability of group column type deep mixing improved ground under embankment loading. Soils Found 47(3):437-455
22. Ishikura R, Ochiai H, Omine K, Yasufuku N, Matsuda H, Matsui $\mathrm{H}$ (2009) Evaluation of the settlement of in situ improved ground using shallow stabilization and floating-type cement-treated columns. Doboku Gakkai Ronbunshuu C, vol 65, no. 3, pp 745-755

23. Chai JC, Hino T, Kirekawa T, Miura N (2010) Settlement prediction for soft ground improved by columns. Proc. ICE-Gr. Improv., vol 163, no. 2, pp 109-119

24. Kitazume M (2011) Effect of surface improvement layer on internal stability of group type deep mixing improved ground under embankment loading. p 20

25. Nguyen B, Takeyama T, Kitazume M (2016) External failure of deep mixing columns reinforced by a shallow layer beneath an embankment. J JSCE 4(1):92-105

26. Beasley DH, James RG (1976) Use of a hopper to simulate embankment construction in a centrifugal model. Geotechnique 26(1):220-226

27. Takemura J, Kondoh M, Esaki T, Kouda M, Kusakabe O (1999) Centrifure model tests on double propped wall excavation in soft clay. Soils Found 39(3):75-87

28. Horii N, Toyosawa Y, Tamate S, Hashizume H (2001) Centrifuge model test on the stability of a clayey ground improved by deep mixing method with a low improvement ratio. In: International conferences on recent advances in geotechnical earthquake engineering and soil dynamics, Paper no. 9.36

29. Davies MCR, Parry RHG (1985) Centrifuge modelling of embankments on clay foundations. Soils Found 25(4):19-36

30. Tsuji T, Kitazume M (2013) Centrifuge model tests and numerical analyses on stability of soft clay slope improved by column type deep mixing method. Tokyo Institute of Technology

31. Take WA, Bolton MD, White DJ (2003) Soil deformation measurement using particle image velocimetry (PIV) and photogrammetry. Géotechnique 53(7):619-631

32. Zhang YD, Tan TS, Leung CF (2005) Application of particle imaging velocimetry (PIV) in centrifuge testing of uniform clay. Int J Phys Model Geotech 5(1):15-26

33. White DJ, Take WA (2002) GeoPIV: particle image velocimetry (PIV) software for use in geotechnical testing. Technical Report No: CUED/D-SOILS/TR322. Geo PIV. Cambridge University Engineering Department

34. Dracos T (1996) Partical tracking velocimetry. In: Dracos T (ed) Three-dimensional velocity and vorticity measuring and image analysis techniques. Springer, pp 155-256

35. Murthy TG (2013) Evolution of deformation fields in 1-g model tests of footings on sand. In: ICPMG2014-physical modelling in geotechnics. CRC Press, pp 653-657

36. Tatarniuk C, Bowman E (2012) Case study of a road embankment failure mitigated using deep soil mixing. In: Grouting and deep mixing 2012, pp 471-482

37. Zheng G, Diao Y, Li S, Han J (2013) Stability failure modes of rigid column-supported embankments. In: Geo-Congress 2013, pp 1814-1817 